\title{
Strategic Implementation of “Everyday Low Price” in Electronic Markets: A Study of Airline Pricing on the Internet
}

\author{
Raymond G. Sin \\ School of Business and Management \\ Hong Kong University of Science and Technology \\ Clear Water Bay, Hong Kong \\ rsin@ust.hk \\ Phone: (852) 2358-7632 \\ Fax: (852) 2358-2421 \\ Ramnath K. Chellappa \\ Goizueta Business School, Emory University \\ Atlanta, GA 30322-2710 \\ ram@bus.emory.edu \\ Phone: (404) 727-7599 \\ Fax: (404) 727-2053 \\ S. Siddarth \\ Marshall School of Business, University of Southern California \\ Los Angeles, CA 90089 \\ siddarth@usc.edu \\ Phone: (213) 740-5048 \\ Fax: (213) 740-7828
}

First Draft: August 2005

This Version: July 2009 


\title{
Strategic Implementation of "Everyday Low Price" in Electronic Markets: A Study of Airline Pricing on the Internet
}

\begin{abstract}
An Everyday Low Price (EDLP) strategy is a product-portfolio level pricing strategy by which a firm attempts to convey to consumers that prices across its product portfolio are consistently low. Empirically, the EDLP strategy is operationalized along two dimensions; the "everyday" component, which relates to the consistency in product prices over time, and the "low price" component, which implies that the prices set are on average lower than other prices available in the market. There may, however, be specific categories or markets in which even EDLP firms may prefer to eschew their consistency and low price goals. The U.S. domestic airline industry has two airlines that adopt the EDLP format while most others employ a promotional (HILO) pricing strategy, thus providing a rich context to investigate how the EDLP price-image strategy is implemented. We use a web crawler to gather information on over 270,000 ticket prices offered by the major airlines in 472 markets, and use a hierarchical linear model to analyze how these two dimensions of price vary with ticket categories and market conditions - defined in economics literature by advance purchase periods, weekend restrictions, airlines' competitiveness, market distance, and hub operations.

We find that the EDLP airlines emphasize the everyday dimension of their pricing much more than the low price dimension. Thus while their prices are systematically more consistent than their HILO competitors, their price levels show that they practice the same form of price discrimination with advance-purchase periods as their HILO competitors. Interestingly, while most airlines charge higher prices for tickets without weekend restriction, which are typically targeted towards business travelers, EDLP firms charge lower prices for these tickets. Further investigation at a category level reveals that these lower business fares are distinct features of short-haul markets where EDLP firms are known to enjoy certain cost advantages due to smaller equipment sizes of their flights. From the "everyday" point of view, we see that while there are no differences in the consistency of prices of EDLP tickets based on advance purchase periods, prices of business-focused EDLP tickets are distinctly more consistent than those of leisureoriented tickets. Curiously, even in markets where EDLP firms are monopolists, they do not appear to be exercising their monopoly power; on the other hand, HILO firms distinctly employ discriminatory pricing in their monopoly markets. Perhaps this is a reflection of EDLP firms pursuing a limit-pricing/barrier-to-entry strategy. Our research shows that the practice of EDLP in online markets involves strategic variations in how price image is communicated.
\end{abstract}

Keywords: Everyday low price (EDLP), competition, airline industry, Internet, hierarchical linear models 


\section{INTRODUCTION}

Many retailers strategically choose to create and maintain a certain price image among consumers by employing particular pricing strategies for their product portfolio (Ortmeyer et al. 1991). While "Dollar Stores”, 99 cent price-endings, etc., fall in this category, one other key approach is through the employment of specific price-formats; i.e. the "everyday low price" (EDLP) and the price-promotion (HILO) format (Bell and Lattin 1998). These price formats are geared towards setting prices for a portfolio of products rather than individual ones: while the EDLP strategy is generally associated with charging consistent (symbolized by the "everyday” part) and low average prices, the HILO strategy is associated with deals, discounts and promotions. In the retail sector, the success of the EDLP strategy is related to the presence of time-constrained consumers who are not able or willing to shop around, as well as large basket shoppers whose store choice decisions rely heavily on the expected overall basket price (Lal and Rao 1997; Bell and Lattin 1998). Although the practice of EDLP has been studied largely as a component of retail competition (mostly in the context of grocery stores and supermarkets), Hoch et al. (1994) observe that this price-format is also implemented by airlines, automobile manufacturers, warehouse operators and others. Of these various industry contexts, the airline sector in particular provides a rich and interesting context for studying the practice of EDLP for several reasons.

First, there are two prominent airlines, Southwest and JetBlue, that engage in EDLP format pricing while most others practice some form promotional pricing. In fact, a recent study in Information Systems (IS) points out that this asymmetry in vendors' portfolio of prices is one important source of overall price dispersion in the market 
(Chellappa et al. forthcoming). However, while this work has investigated the impact of differential price-image strategies on market-level price dispersion, there is currently little or no understanding on how an EDLP strategy is executed.

Second, two fundamental factors important to the success of EDLP in the physical, retail, supermarket context are not observed in the airline industry. First, the concept of “basket-shopping” is irrelevant. Airline passengers, unlike supermarket shoppers, do not shop for a "basket of products" but typically purchase only one or two tickets at a time while being repeat purchasers over time. Second, geographical separation from competitors is irrelevant because airlines largely sell tickets directly (or through online travel agents) to consumers via online channels (Clarkson et al. 2005), lowering search costs and making it easy for consumers to compare prices. As a result, EDLP strategy itself might be jeopardized, since EDLP prices are the ones that consumers use as a benchmark (reference prices) in their decision to search for deals while comparing prices (Yadav and Seiders 1998). Thus it is important to understand the manner in which EDLP might be implemented as these two airlines continue to be successful.

Third, there are two opposing forces at work when practicing a portfolio pricing strategy in contexts where there is ample opportunity to price discriminate. General economic theory, particularly in models of individual product pricing, argues that when opportunities to segment on the basis on consumer, product, market, or temporal characteristics are available, a firm should engage in price discrimination. On the other hand, the EDLP strategy emphasizes on maintaining consistency in prices and keeping prices generally low even if no single firm can consistently offer the lowest prices for all products in all markets at all times. Therefore, it is likely that even EDLP firms may 
strategically vary their prices depending on the types of products they offer and markets they compete in in, thus positioning themselves differently on the continuum of the two price formats as described in extant research (Hoch et al. 1994; Bell and Lattin 1998). Finally, the requirement to charge low and consistent prices may also be at loggerheads with the economic principles of monopolistic pricing. EDLP carriers do have monopolistic power in some markets, and thus might be expected to charge higher prices in those markets. In fact, Borenstein and Rose (1994) find evidence of monopolistic pricing in certain airline routes, although for non-EDLP carriers. If EDLP firms were to engage in monopolistic pricing in those markets, we might expect to observe some departure from their overall pricing practice in competitive markets. Thus, it is important investigate how an EDLP firm strategically manages its "everyday" and "low price" dimensions of the price-format in different markets.

To do so, our research first establishes empirical metrics from marketing literature to capture these two dimensions. We also use the existing research on pricing in the airline industry to identify different market and competitive conditions that airlines face when setting prices. We develop and estimate hierarchical model that accounts for partial dependence among prices due to market- or airline-dependent factors, using pricing data for over 270,000 tickets offered by fourteen major carriers in 472 domestic air travel markets. Coefficient estimates from this analysis form the basis of our examination of how the price-setting of EDLP firms change with underlying market conditions. Further, we also examine how the underlying low price and everyday dimensions for EDLP airlines are different from HILO airlines and change with market conditions. 
The remainder of the paper is organized as follows. Section 2 presents the motivation for this paper based on relevant theories from existing literature. Section 3 discusses the data and empirical models employed in this study, which is followed by a summary of results in Section 4. Section 5 concludes with implications and directions for future research.

\section{THEORY AND MOTIVATION}

Our research and analysis informed by three streams of literature related to: 1) retail price formats; 2) airline pricing and competition; and 3) price discrimination and online pricing.

It should first be noted that our knowledge of how price-image strategies are implemented comes mainly from previous studies in the marketing literature of how grocery stores price packaged goods. This research has established that the price-image of a firm is critical component of its overall strategy and a key determinant of the types of customers a store attracts (Alba et al. 1994; Desai and Talukdar 2003). A retailer’s overall pricing strategy begins with a choice of price format, which typically lie along a continuum between the Everyday Low Pricing (EDLP) and Promotional pricing (PROMO or HILO) formats (Shankar and Bolton). EDLP sellers generally provide little or no temporal price discounts, while charging prices that are lower than the average prices of their HILO competitors. The marketing literature suggests that EDLP prices may be as low as 9\% below their HILO counterparts (Hoch et al. 1994). Their goal is to establish a general "low price" image to convince consumers that "regardless of what or when you purchase, you can always expect below-average prices at our stores”. HILO sellers, on the other hand, charge prices that are higher on average while also engaging in frequent promotions to undercut EDLP prices. They emphasize that exceptional 
values are periodically available at their stores and encourage consumers to visit frequently to discover the deals (Lattin and Ortmeyer 1991; Hoch et al. 1994; Lal and Rao 1997; Bell and Lattin 1998; Ho et al. 1998).

Successful implementation of price-image strategies depends upon consumers’ price knowledge (or lack thereof) and their (un)willingness to search for deals. For an EDLP airline to be successful, it is essential that either a) a sufficient number of consumers are uninformed about lower prices in the market and unwilling to search due to high costs of searching, and/or b) EDLP airlines always offer the lowest prices in the market. The second condition is unlikely since it is rare for a firm to always charge the lowest price; while the first condition is also increasingly difficult to maintain in an industry with intermediaries such as online travel agents that facilitate price comparisons. Thus there is sufficient reason to investigate how this strategy is practiced by airlines that are proponents of EDLP.

Theory suggests that the practice of EDLP and HILO can be examined along at least two dimensions of their price distributions. The first is price level (the "low price" component of EDLP): The general idea behind EDLP pricing is that a consumer, without searching, would expect EDLP firms to charge lower prices. Thus a firm practicing EDLP should be expected to set prices that are lower than average, irrespective of product category. The second dimension is one of price consistency (the "everyday" part of its price image). EDLP prices are in general more consistent or less variable than market prices, and literature finds this to be the case in many retail sectors (Shankar and Bolton 2004). Research in this area also notes that this does not necessarily mean that EDLP firms do not offer price discounts, but rather the frequency and magnitudes of 
discounts offered by EDLP firms are smaller than those of their HILO counterparts. Hence while EDLP does not imply constant or static pricing, it is associated with prices that are more consistent than those at HILO stores in the market (Hoch et al. 1994; Ho et al. 1998; Shankar and Bolton 2004). These empirical observations are also consistent with findings of game-theoretic models of Lal and Rao (1997) and Lattin and Ortmeyer (1991), where equilibrium EDLP prices exhibit greater price consistency (less variability) and lower price levels. Thus in the airline context also we should expect more consistency in prices of EDLP airlines, perhaps across all different categories it competes in. The existing literature has identified a number of factors that influence airline pricing such as consumer segments, distance and other market characteristics, and the operational and cost structures of airlines. However, it is important to note that all of these findings come from studies of HILO airlines such as American and United, and whether they influence EDLP airline pricing in the same way remains an open question.

Our empirical analysis accounts for the potential influence of these factors and provides insights into whether and how the level and consistency of EDLP airline prices varies across different market conditions The following sub-sections provides a brief discussion of how these factors related to the current research. Previous research on airline competition as well as recent research in IS has shown that prices are routespecific, i.e. independent of whether an airline is an EDLP practitioner or not, ticket prices (and price distribution) might vary depending upon whether is ticket is LAX-JFK or ATL-JFK (Chellappa et al. forthcoming). However, this work has not examined whether and how the price-level and consistency of EDLP prices might vary between these two routes, i.e. do firms strategically alter the manner in which they practice this 
price format, perhaps because its market power in each route is different? In order to examine such strategic differentiation by EDLP firms, we need to first understand the relevant classification that is followed in this industry.

\subsection{Everyday low pricing and consumer segments}

Airline tickets are defined by many attributes and the same airline offers several ticket variants for the same origin-destination pair. Airlines create differentiated products by imposing various restrictions on the tickets and pricing them to target different consumer segments based on their willingness to pay (Gale and Holmes 1993; Dana 1998; Stavins 2001; Clemons et al. 2002). For example, previous studies have found that ticket prices increase closer to the departure date approaches so that consumers with a higher opportunity cost of time pay higher prices (Dana 1998; Stavins 2001). Similarly, prices for tickets that include a Saturday night stay-over have been found to be cheaper than those that do not impose this requirement The general rationale behind both advancepurchase periods and weekend restrictions is that business travelers place a higher value on flexibility while leisure travelers will be willing to bear some inconvenience for a cheaper price.

It is unclear, however, how an airline that is committed to conveying an EDLP image will calibrate its prices to take advantage of these natural differences in consumers' willingness to pay. Will an EDLP airline also charge lower prices for tickets purchased well in advance and for those that impose a Saturday night stay-over? Or will it adopt a different approach in order to differentiate themselves from its HILO competitors? If it does adopt a different approach, which dimension of its EDLP strategy 
will it emphasize, "ED” or LP? These are some of the questions that our research seeks to answer.

\subsection{Everyday low pricing, market power and operational infrastructure}

Market characteristics, such as the distance between origin and destination airports or whether one of them happens to be a "hub," have been found to play an important role in airlines’ pricing. Hub-and-spoke systems allow for more efficient use of aircraft, and provide additional values to consumers through greater flight frequency and easier connections. Previous research shows that HILO airlines may enjoy market power from economies of scale due to large presence in particular airport(s) or route(s), and control over scarce resources such as the use of gates and runways (Berry 1990), allowing it to command a price premium from consumers, while also creating barrier to entry by competitors. On the other hand, hub operations may enable an airline to realize cost saving due to economies of scale, though these savings may not necessarily be passed on to the consumers (Borenstein 1989; Berry et al. 1997). HILO airlines also calibrate their prices based on the competitive environment where intense competition among many airlines with small market shares leads to lowering of their prices (Borenstein and Rose 1994; Hayes and Ross 1998; Stavins 2001).

While there is ample evidence that hub-based and market share-based pricing is quite common in the airline industry, it is not known whether EDLP airlines will also prefer to price discriminate based on these elements in the same manner as their HILO counterparts, or if their portfolio level pricing strategy will trump any market power considerations. 
From an operational point of view, while large airplanes allow for economies of scale for longer flights, variable costs also increase in proportion relative to the fixed costs of takeoff and landing (Borenstein 1989; Berry et al. 1997; Hayes and Ross 1998; Stavins 2001). Such operational costs of airlines can play a direct and obvious role in ticket prices set by HILO airlines, e.g., higher costs of operation implies higher prices so as to cover the expenses of providing services in a given route (Borenstein 1989). Other important factors that influence airlines' cost are efficiency of aircraft utilization, and equipment size and variety. Aircraft utilization is generally greater in routes with high flight frequency, which lowers the per-flight costs and potentially also the ticket prices; but at the same time, greater flight frequency lowers frequency delay and increase the value of the ticket. HILO airlines have been known to utilize this factor to command higher ticket prices (Borenstein 1989).

On the other hand, while large aircrafts benefit from economies of scale on fuel in long-haul routes, smaller aircrafts may be more cost-effective in short-haul markets due to high fixed costs of takeoffs and landings (Borenstein 1989; Berry et al. 1997). In fact, operating and maintaining a small variety of airplanes has been reported as an important cost-saving measure (Neels 2000). Interestingly, EDLP airlines in domestic U.S. market generally tend to operate mid-size planes that are most fuel efficient for traveling a nonstop distance of less than 500 miles. For example, Southwest Airlines operates only Boeing 737 flights with sizes ranging from 122 to 137 seats; while JetBlue Airways operate two types of flights: the Airbus A320 with 156 seats, and the EMBRAER 190 with 100 seats $^{1}$. Compared to their HILO counterparts, these airlines potentially enjoy

\footnotetext{
1 At the time of our data collection, JetBlue had not yet introduced the EMBRARER and was only operating the A320.
} 
significant cost advantage and logistical efficiency in short-haul markets. Greater equipment variety of HILO carriers also imply significant costs arising from vastly different maintenance crews, gates and runways utilization, and different levels of seats and services, etc. What is not known, however, is whether EDLP airlines strategically vary their prices based on these distinct differences in operational abilities. On the one hand, EDLP airlines might enjoy the cost advantages but continue their consistent pricing approach; while on the other, they could eschew their consistency goal and use these cost advantages to undercut competitors' prices. Our research empirically investigates the strategic variation in pricing that EDLP airlines pursue. In addition, by carrying out our analysis in both competitive and monopoly markets, we also shed light on how implementation of the EDLP strategy varies with the competitive environment.

\section{DATA AND METHOD}

In this section, we first discuss the nature of our data and explain the econometric model employed in this study. We then discuss how the everyday and low price dimensions of price are operationalized and conclude with a discussion of the variables used in our econometric analysis.

\subsection{Data}

Our data is collected from two primary sources. First, we obtained prices and detail descriptions of airline tickets from online travel agents and individual airlines’ websites. This raw data was gathered using web-based spiders that we developed using Curl, and later processed by a parser that we wrote in Perl and other database scripting languages. In addition to the set of major U.S. carriers and online travel agents, a list of the top 500 
U.S. domestic routes - which account for over $86 \%$ of all domestic passenger enplanements in the U.S. - was provided as input to the spiders. The spiders were sent out on a daily basis in the third quarter of 2004 to collect price and other attribute information for tickets requiring one- to four-week advance purchases, including weekday as well as weekend departures and returns. Our agents operated in parallel and submitted identical reservation requests to all online travel agents and airlines' websites simultaneously in order to minimize price variations that may arise from the timing of ticket requests.

Consistent with prior research on airline pricing, we consider only coach class, non-refundable, roundtrip tickets. Further, to control for any price difference that may be attributed to differences in flight duration or the number of connections on any given route, we restrict our attention to direct, non-stop, flights between an origin and a destination. Since non-stop flights were not available in 28 routes, our final data set includes 472 markets and 272,362 unique tickets and final prices, including taxes and fees, offered by fourteen network carriers..

Second, we used the Air Carrier Statistics (Form 41 Traffic and 298C Summary Data) and Air Carrier Financial Reports (Schedule P-12) provided by the U.S. Bureau of Transportation Statistics to assemble data on airlines’ operational details (e.g. cost per available seat-mile, aircraft types and sizes, frequency of flights, etc.), as well as information on the respective markets (e.g. origin-destination distance, hub information, etc.). In addition, we used the Origin and Destination Survey (DB1B) for the corresponding routes and carriers in the second and third quarters of 2004 to collect information on market share and the number of competing airlines in each origin- 
destination pair from the Origin and Destination Survey (DB1B) for the corresponding routes and carriers in the second and third quarters of 2004. DB1B is a $10 \%$ sample of all airline tickets sold by reporting carriers, including origin, destination and other itinerary details of passengers transported.

When merged with the pricing data, this yielded a complete profile of all relevant variables at the ticket level that allowed us to examine the effects of various market- and airline-specific factors on airline pricing

We subsequently divided the full dataset into three subsets to separately analyze airlines’ pricing in competitive versus monopoly markets. The first subset includes tickets offered by both EDLP and HILO airlines in 268 markets in which at least two airlines compete. The second subset includes only EDLP observations in 114 markets in which EDLP airlines operate. The third subset includes only HILO observations in 405 markets that are served by HILO carriers. Table 1 summarizes the operationalization of variables included in this study; and Tables 2 and 3 report descriptive statistics for our data.

\subsection{Models}

An important characteristic of the data is that prices of individual tickets (level 1) are clustered within groups defined by the airline/route (level). Thus, prices of tickets written by a particular carrier are likely to be correlated due to the underlying pricing strategy, or the cost and operational structure of the airline. Similarly, ticket prices of different airlines in the same market (defined as a directional origin-destination pair) may also be correlated because of the common underlying demand characteristics, competitive forces and cost structure for that route. When data are clustered in this fashion the 
resulting unit-level random errors are correlated (within group) and heteroscedastic (across groups), thus violating two critical assumptions of OLS.

Hierarchical linear models (HLM) provide a way to overcome these problems by extending traditional regression models to account for the partial dependence of individual observations within a group and for heterogeneity across groups. This approach has been recommended for the analysis of airline data by Borenstein and Rose (1994), as well as in two recent studies of price dispersion in the area of information systems by Venkatesan, Mehta and Bapna (2006) and Chellappa, Sin and Siddarth (forthcoming).

The fundamental idea behind HLM is that separate analyses are performed for each of the units at the lowest level of a hierarchical structure, while both individual- and group-level unit variances in the outcome measure are examined through simultaneous estimation of between-group variances and the effects of independent variables at each level. The total variance in the outcome is then divided into the parameter variance and error variance components. Unlike OLS, hierarchical models estimate residuals from different levels separately and account for the covariance structure among group-level regression estimates; not only does this provide more accurate group effect estimates than traditional methods that systematically underestimate them (Raudenbush and Bryk 1989), but it also allows one to model explicitly both within- and between- group variances as well as their effects on the outcome while maintaining the appropriate level of analysis (Griffin and Hofman 1997).

One additional advantage of the HLM approach, which is also critical for this research, is that it allows us to incorporate airline and market characteristics into the 
model while still producing accurate estimates of the group-level effects and valid tests of confidence intervals (Mendro et al. 1995) - which are typically ignored by OLS (Bryk and Thum 1989). In addressing the multilevel nature of data, traditional fixed effects models use dummy variables to "absorb” all heterogeneities across different group units; as a result, level-two variables (airline and route characteristics) are excluded from the model because they are confounded with the group fixed effects (airline and route dummies) and cause multicollinearity problems. In our current context, this implies that airline- and market-specific attributes cannot be explicitly accounted for in a fixed effects model, thus largely limiting our ability in drawing inferences on the mediating effects of these characteristics on the relationship between other explanatory variables (such as pricing strategy) and ticket prices. While typically this can be resolved by incorporating interactions between the explanatory variables and group-level dummies into the model, when the number of groups (such as origin-destination pairs) is large, the interaction approach becomes impractical as it results in a large number of parameters and overidentification of the model.

In the subsequent discussions, we use subscript $m$ to denote a market and subscript $k$ to denote a carrier. Model 1 investigates the "low-price" dimension of EDLP using ticket-level prices (dependent variable: price $_{i k m}$ ), while Model 2 examines the “everyday” dimension using the variance in prices of individual carriers within each market (dependent variable: $C V_{k m}$ ). We treat both airline and route effects as random in Model 1; this is because level-1 units (individual tickets) are cross-classified by two separate level-2 units (airline and market). In Model 2, however, the dependent variable 
is an aggregate measure at the airline level. Following extant literature we treat only the route effect as random (Borenstein and Rose 1994).

\section{Model 1: The "low-price” dimension}

We employ the log form for most of our explanatory variables because it captures the declining marginal effects of these variables on prices, which is consistent with existing research on airline pricing as well as the actual pricing practices of airlines. The only exceptions are: 1. dummy variables, because taking log would not be reasonable or possible; 2. Market share (RTshare) and the corresponding Herfindahl index (RTherf), because it is more reasonable to assume that increase in an airline's route share would have a proportional (rather than declining) effect on price (Borenstein 1989).

Level 1 (ticket-level) model:

$$
\begin{aligned}
\ln \left(\text { price }_{i k m}\right) & =\alpha_{0 k m}+\alpha_{1 k m} B U S_{i k m}+\alpha_{2 k m} D D 7_{i k m}+\alpha_{3 k m} D D 14_{i k m}+\alpha_{4 k m} D D 21_{i k m}+\varepsilon_{i k m} \\
\varepsilon_{i k m} & \sim N\left(0, \sigma^{2}\right)
\end{aligned}
$$

Level 2 (airline- and market-level) model:

$$
\begin{aligned}
\alpha_{0 k m}= & \beta_{0}+\gamma_{01} E D L P_{k}+\gamma_{02} \ln \left(\text { freq }_{k m}\right)+\gamma_{03} h b_{k m}+\gamma_{04} \text { RTshare }_{k m} \\
& +\gamma_{05} \text { RTherf }_{m}+\gamma_{06} \text { Shorthaul }_{m}+\gamma_{07} \ln \left(\text { CASM }_{k}\right)+\gamma_{08} \ln \left(\text { EQUIPsize }_{k m}\right) \\
& +\gamma_{09}\left(E D L P_{k} \times \text { shorthaul }_{m}\right)+\gamma_{10}\left(E D L P_{k} \times h u b_{k m}\right)+u_{00 k}+u_{00 m}+u_{0 k m} \\
\alpha_{1-4 k m}= & \gamma_{1-4 k m}+\delta_{1-4 k m} E D L P_{k} \\
u_{00 k} & \sim N(0, \varphi) \\
u_{00 m} & \sim N(0, \tau) \\
u_{0 k m} & \sim N(0, \psi)
\end{aligned}
$$

The full model (after rearranging terms and renaming the coefficients):

$$
\begin{aligned}
\ln \left(\text { price }_{i k m}\right)= & \alpha+\beta_{1} E D L P_{k}+\beta_{2} \text { BUS }_{i k m}+\beta_{3} D D 7_{i k m}+\beta_{4} D D 14_{i k m}+\beta_{5} D D 21_{i k m} \\
& +\beta_{6} \ln \left(\text { freq }_{k m}\right)+\beta_{7} \text { hub } b_{k m}+\beta_{8} \text { RTshare }_{k m}+\beta_{9} \text { RTherf }_{m} \\
& +\beta_{10} \text { shorthaul }_{m}+\beta_{11} \ln \left(C A S M_{k}\right)+\beta_{12} \ln \left(E Q U I P s i z e_{k m}\right) \\
& +\beta_{13}\left(E D L P_{k} \times B U S_{i k m}\right)+\beta_{14}\left(E D L P_{k} \times D D 7_{i k m}\right)+\beta_{15}\left(E D L P_{k} \times D D 14_{i k m}\right) \\
& +\beta_{16}\left(E D L P_{k} \times D D 21_{i k m}\right)+\beta_{17}\left(E D L P_{k} \times \text { shorthaul }_{m}\right)+\beta_{18}\left(E D L P_{k} \times h u b_{k m}\right)+\varepsilon_{i k m}
\end{aligned}
$$


where

$$
\alpha=\beta_{0}+u_{00 k}+u_{00 m}+u_{0 k m}
$$

Equation (3) is the basic model to be estimated. The dependent variable price $i k m$ denotes the price of ticket $i$ offered by carrier $k$ in market (route) $m$. Interactions between EDLP and various ticket categories (Saturday night stay-over and advance purchase periods) and market characteristics (short-haul and hub) are included to capture any potential effects on prices set by EDLP airlines as a result of their varying the pricing strategy for different product categories or market types. $\beta_{0}$ represents the overall intercept; $u_{00 k}$ and $u_{00 m}$ are the random carrier and route effects, respectively. $u_{0 k m}$ is the random interaction effect. Finally, $\varepsilon_{i k m}$ is the white-noise error particular to the individual observation.

It should be noted that the variable BUS identifies tickets without the Saturday night stay-over restriction, which are targeted towards business travelers; it does not represents "business class" tickets. All tickets in our sample are restricted coach class tickets. For brevity and consistency with existing literature (Chellappa et al. forthcoming), we shall refer to tickets without weekend restriction as "business tickets", while those that are with such restriction as "leisure tickets".

\section{Model 2: The “everyday” dimension}

Level 1 (airline-level) model:

$$
\begin{aligned}
C V_{k m} & =\alpha_{0 m}+\alpha_{1 m} E D L P_{k}+\alpha_{2 m} B U S_{k m}+\alpha_{3 m} D D 7_{k m}+\alpha_{4 m} D D 14_{k m}+\alpha_{5 m} D D 21_{k m} \\
& +\alpha_{6 m} \text { freq }_{k m}+\alpha_{7 m} h u b_{k m}+\alpha_{8 m} \text { RTshare }_{k m}+\alpha_{9 m} \text { CASM }_{k}+\alpha_{10 m} \text { EQUIPsize }_{k m}+\varepsilon_{k m} \\
\varepsilon_{k m} & \sim N\left(0, \sigma^{2}\right)
\end{aligned}
$$

Level 2 (market-level) model: 


$$
\begin{aligned}
\alpha_{0 m}= & \beta_{0}+\gamma_{11} \text { RTherf }_{m}+\gamma_{12} \text { shorthaul }_{m} \\
& +\gamma_{13}\left(\text { EDLP }_{k} \times \text { shorthaul }_{m}\right)+\gamma_{14}\left(E D L P_{k} \times h u b_{k m}\right)+u_{0 m} \\
\alpha_{1 m}= & \gamma_{1 m} \\
\alpha_{2-5 m}= & \gamma_{2-5 m}+\delta_{2-5 m} E D L P_{k} \\
\alpha_{5-10 m}= & \gamma_{5-10 m} \\
u_{0 m} & \sim N(0, \tau)
\end{aligned}
$$

The full model (after rearranging terms and renaming the coefficients):

$$
\begin{aligned}
C V_{k m}= & \alpha+\beta_{1} E D L P_{k}+\beta_{2} B S_{k m}+\beta_{3} D D 7_{k m}+\beta_{4} D D 14_{k m}+\beta_{5} D D 21_{k m} \\
& +\beta_{6} \text { freq }_{k m}+\beta_{7} h u b_{k m}+\beta_{8}{\text { RT } \text { share }_{k m}+\beta_{9} \text { RTherf }_{m}} \\
& +\beta_{10} \text { shorthaul }_{m}+\beta_{11} \text { CASM }_{k}+\beta_{12} \text { EQUIPsize }_{k m} \\
& +\beta_{13}\left(E D L P_{k} \times B U S_{k m}\right)+\beta_{14}\left(E D L P_{k} \times D D 7_{k m}\right)+\beta_{15}\left(E D L P_{k} \times D D 14_{k m}\right) \\
& +\beta_{16}\left(E D L P_{k} \times D D 21_{k m}\right)+\beta_{17}\left(E D L P_{k} \times \text { shorthaul }_{m}\right)+\beta_{18}\left(E D L P_{k} \times h u b_{k m}\right)+\varepsilon_{k m}
\end{aligned}
$$

where

$$
\alpha=\beta_{0}+u_{0 m}
$$

The dependent variable in Model 2 is the coefficient of variation of prices, which is constructed from the set of all tickets written by an airline in a particular route $\left(I_{k m}\right)$ for a given ticket category (defined by ticket restrictions, namely Saturday night stay-over and advance purchase period) and market type (defined by short-haul and hub) ${ }^{2}$ :

$$
C V_{k m}=\frac{\sqrt{\frac{1}{I_{k m}-1} \sum_{i}^{I_{k m}}\left(\text { price }_{i k m}-\overline{\text { price }_{k m}}\right)^{2}}}{\overline{\text { price }_{k m}}} \text {, where } \overline{\text { price }_{k m}}=\frac{1}{I_{k m}} \sum_{i}^{I_{k m}} \text { price }_{i k m}
$$

Note that since the unit of analysis in this model is at the carrier-route level, it requires that only one random effect be included in the model. Consistent with Borenstein and Rose (1994), we treat the route effect $\left(u_{0 m}\right)$ as random while capturing the airline effects using airline-specific variables (EDLP and CASM).

\footnotetext{
${ }^{2}$ For exposition brevity, superscripts that denote the ticket category and market type are suppressed from equations (5)-(9).
} 


\subsection{Econometric issues}

It is reasonable to expect that an airline's share of passenger on a route (RTshare), as well as the Herfindahl index constructed from this variable (RTherf), to be endogenous to the price that it charges; in fact, a Hausman specification test does reject exogeneity for RTshare and RTherf . We tackle this problem as follows: at the conceptual level, we construct RTshare based on market share information obtained from the second quarter of 2004 (one quarter prior to our data collection); hence it is reasonable to argue that prices of tickets offered by an airline (in the current period) is a function of its market share (in the previous period), rather than the other way around. However, if market shares of the respective airlines are relatively stable - which is indeed the case for most of the routes then statistically the potentially endogenous variables can still be correlated with the error term. We resolve this issue at the empirical level using instrumental variable and the two-stage least square approach. Following Borenstein (1989) and Borenstein and Rose (1994), we use the geometric share of enplanements of an observed carrier at the endpoints of a given route as the instrument for its market share, and later use it to construct the instrument for RTherf . The geometric enplanement share of the observed airline $i$ on a given route is defined as follows:

$$
\text { GENPSH }_{i}=\frac{\sqrt{E N P_{i 1} \cdot E N P_{i 2}}}{\sum_{j} \sqrt{E N P_{j 1} \cdot E N P_{j 2}}}
$$

where $j$ indexes all airlines; $E N P_{j 1}$ and $E N P_{j 2}$ are airline $j$ 's average daily passenger enplanements at the two endpoint airports on the observed route during the second quarter of 2004. In other words, $\mathrm{GENPSH}_{i}$ is defined as the observed carrier's geometric mean of passenger enplanements at the endpoints of a route divided by the sum of the 
geometric mean of each carrier's enplanements at the endpoint airports across all carriers on the observed route.

We construct the instrument for RTherf using the square of the fitted value $\widehat{\text { RTshare }}$ from the first-stage regression, plus a rescaled sum of squares of the shares of all other carriers:

$$
\text { IRTherf }=\widehat{\text { RTshare }}_{i}^{2}+\frac{\text { RTherf }- \text { RTshare }_{i}^{2}}{\left(1-\text { RTshare }^{2}\right.} \cdot\left(1-\widehat{\text { RTshare }}_{i}\right)^{2}
$$

where $i$ indexes the observed airline. The rationale behind the second term in IRTherf is that the concentration of traffic on a route that is not served by the observed airline is exogenous to the price of the observed airline; for example, Delta's price on the BostonLaGuardia Airport route does not affect the division of passengers between American and United. The rescaling ensures that the part in a Herfindahl index that is calculated for passengers who do not travel on the observed carrier remains unchanged. We then use IRTherf as the excluded exogenous variable in the first-stage regression of $R$ Therf that generates $\widehat{R T h e r f}$.

Careful readers may notice that in Model 1, RTshare is correlated not with the error at the individual ticket level $\left(\varepsilon_{i k m}\right)$ but instead with the level-2 random interaction effect $\left(u_{0 k m}\right)$; the reason is that $R T$ share is defined at the carrier-route level, which is ticketinvariant. Standard procedures in the instrumental variable approach ignore the level-1invariant nature of the latent effect, yielding an estimator that is biased at best (and inconsistent at worst). We employ a method that makes use of the information available from level-1 exogenous variables in constructing the level-2 instrument based on Hausman and Taylor (1981). The basic idea behind this approach is that the effects of 
each level-1 exogenous variable in a level-2 instrument can be approximated by its mean at the corresponding level; hence the means of exogenous ticket-varying variables (e.g. $D D 7$ ), along with other ticket-invariant exogenous variables (e.g. freq), can be use as instruments for the endogenous ticket-invariant variables. Similar approach has been used in various contexts such as studies on the sales of the cereal products (Nevo 2001) and diffusion of new pharmaceutical drugs (Desiraju et al. 2004).

\section{RESULTS}

In order to specifically assess the impact of competition on the EDLP strategy, we separately analyze markets in which either the EDLP airlines or the HILO airlines are monopolists. Section 4.1 discusses the model specification tests from our investigation of competitive markets (at least one EDLP and one HILO airline present). These include the multicollinearity test, Hausman test, and robustness tests based on analysis on the residuals, as well as various goodness of fit indexes (due to space consideration we present results from our specification tests only for model 1). Further, we explain how we arrive at the final coefficients from which we draw inferences in sections 4.2 to 4.4. Section 4.2 compares the pricing behaviors of EDLP carriers to those of their HILO counterparts. Section 4.3 discusses the strategic variation in the two dimensions of EDLP, namely “everyday" and "low price”, respectively. Section 4.4 examines the potential monopolistic pricing behaviors of EDLP and HILO airlines separately.

\subsection{Test of Model Specification and Robustness}

The two highest VIF values are 5.32 and 4.94, both below the critical level of 10, which indicates that multicollinearity is not an issue in our model. Further, Hausman tests were 
performed for the route random effects and airline random effects. The null hypothesis is equality of fixed- and random-effects estimates. The resulting test statistic is 0.1673 , which falls well below the critical value of 29.14 at the 99 percent confidence level for a Chi-square with 14 degrees of freedom ${ }^{3}$. These statistics indicate that the coefficient estimates from the random effects model are not significantly different from those that are obtained from the fixed effects model, and that the random effects specification produces consistent results. Further, from the first three rows in Table 4 we can observe that the estimates of the airline- and route-route random effects are highly significant from the Null HLM. These statistics suggest that ticket prices are clustered within both carrier and route; hence the results obtained from the fixed effects model would likely be misleading. The last four rows in Table 4 compare the goodness of fit for three different specifications of Model 1: The two-stage least square with fixed effects (2SLS), the null hierarchical model (Null HLM), and the full cross-classified hierarchical model (Full HLM); the former two serve as baseline models for comparison.

The Full HLM fits the data better than the fixed effects model (2SLS) based on both BIC and the sum of residual-squared errors criteria; the sum of squared errors of the Full HLM is lower than that of the fixed effects model by 5.95\%. The amounts of reduction in variance components $\hat{\varphi}, \hat{\tau}$, and $\hat{\psi}$ suggest that $72.05 \%$ of explainable variation in carrier means, $20.65 \%$ of explainable variation in route means, and $24.69 \%$ of explainable variation in the carrier-route means are explained by the variables incorporated in the Full HLM. In addition, the random error is reduced by $14.90 \%$

\footnotetext{
${ }^{3}$ The set of explanatory variables used in the Hausman test are: BUS, DD7, DD14, DD21, lnfreq, hub, RTshare, InEQUIPsize, EDLP*BUS, EDLP*DD7, EDLP*DD14, EDLP*DD21, EDLP*shorthaul, and EDLP*hub. Variables that are captured by either airline- or route-fixed effects are excluded.
} 
compared to the null model. All statistics indicate that the chosen variables provide excellent explanations for the pricing of airline tickets in the sample.

As previously stated, the econometric specification of Model 1 pertains to the analysis of the "low-price" dimension and provides insights about EDLP price levels relative to their competitors. The raw coefficient estimates of this model are presented in Table 5. Because the model includes several variables that interact with the EDLP dummy, care must be taken in inferring the main and interaction effects and in deriving overall implications from the model.

Table 5 shows that main effect of EDLP is positive and significant. The interpretation of this coefficient, which takes into account the baseline values of all the dummies in this model, is that EDLP prices of the 4-week advance purchase leisure tickets for non-hub long-haul sectors are higher than HILO prices for tickets in the same category. In other words, overall EDLP airlines do not necessarily price lower than their HILO counterparts, i.e., not only does "low price” not mean lowest prices, but indeed EDLP prices can even be higher under certain circumstances. Along the same lines, the EDLP coefficient in Table $8^{4}$ (raw coefficient estimates from Model 2), can be interpreted to mean that EDLP prices are more consistent than HILO prices for 4-week advance purchase tickets and non-hub, long-haul sectors.

Tables 6 and 9 provide a "within airlines" analysis that shows respectively how price levels and price consistency of tickets in the first column differ from those in the baseline column. The coefficient estimates reported in Tables 6 are 9 obtained by summing the raw coefficient estimates of the corresponding variables that appear in Tables 5 and 8, respectively. The standard errors for the final estimates are calculated

\footnotetext{
${ }^{4}$ Flight frequency (freq) has been dropped from the analysis due to multicollinearity problem.
} 
using the corresponding elements in the variance-covariance matrix of the Beta coefficients as follows:

$$
\text { S.E. }=\sqrt{\sum_{i} \operatorname{Var}\left(\beta_{i}\right)+\sum_{i \neq j} 2 \operatorname{cov}\left(\beta_{i}, \beta_{j}\right)}
$$

For example, the first row in Table 6 compares EDLP airlines' prices for business tickets (without weekend restriction), versus those for their own leisure tickets (with weekend restriction) - which is the baseline for comparison. The effects of the former can be assessed by summing the intercept, $E D L P, B U S$, and $E D L P \times B U S$ (i.e. $\beta_{0}+\beta_{1}+\beta_{2}+\beta_{13}$ ), while those of the latter can be assessed by summing the intercept and $E D L P\left(\right.$ i.e. $\left.\beta_{0}+\beta_{1}\right)$. The difference between the two, $\beta_{2}+\beta_{13}=-0.1219$, represents the effect of interest; and the standard error is calculated as $\sqrt{\operatorname{Var}\left(\beta_{2}\right)+\operatorname{Var}\left(\beta_{13}\right)+2 \operatorname{cov}\left(\beta_{2}, \beta_{13}\right)}$.

Similarly, the first row, column 1, in Table 7 compares EDLP airlines' prices for business, one-week advance purchase tickets in short-haul, non-hub markets versus those for the same type of tickets in the same type of market offered by HILO airlines. The effects of the former can be assessed by summing the intercept, EDLP, BUS , $D D 7$, shorthaul , $E D L P \times B U S \quad, \quad E D L P \times D D 7 \quad, \quad$ and $E D L P \times$ shorthaul (i.e. $\beta_{0}+\beta_{1}+\beta_{2}+\beta_{3}+\beta_{10}+\beta_{13}+\beta_{14}+\beta_{17}$ ) while those of the latter can be assessed by summing BUS, $D D 7$, and shorthaul (i.e. $\beta_{0}+\beta_{2}+\beta_{3}+\beta_{10}$ ). The difference between the two, $\beta_{1}+\beta_{13}+\beta_{14}+\beta_{17}=-0.2933$, represents the effect of interest; and the standard error is calculated

$$
\sqrt{\begin{array}{l}
\operatorname{Var}\left(\beta_{1}\right)+\operatorname{Var}\left(\beta_{13}\right)+\operatorname{Var}\left(\beta_{14}\right)+\operatorname{Var}\left(\beta_{17}\right) \\
+2 \operatorname{cov}\left(\beta_{1}, \beta_{13}\right)+2 \operatorname{cov}\left(\beta_{1}, \beta_{14}\right)+2 \operatorname{cov}\left(\beta_{1}, \beta_{17}\right)+2 \operatorname{cov}\left(\beta_{13}, \beta_{14}\right)+2 \operatorname{cov}\left(\beta_{13}, \beta_{17}\right)+2 \operatorname{cov}\left(\beta_{14}, \beta_{17}\right)
\end{array}} .
$$

The remaining numbers presented in Tables 6, 7, 9, 10 are obtained in a similar fashion. 
Tables 7 and 10 present a "between airline" analysis, which contrasts the performance of EDLP and HILO airlines on each dimension while Tables 6 and 9 provide a "within airline" analysis provide insights into how the pricing dimensions of EDLP airline vary by product, and market conditions. We discuss these findings in sections 4.2 and 4.3 , respectively.

\subsection{EDLP strategy vis-à-vis HILO pricing}

Our first goal is to examine where there is any statistical difference between EDLP and HILO prices and their distribution. In general, we should expect that EDLP prices are on average lower than their HILO counterparts, while being more consistent. If it is not so then it lends credence the earlier arguments that just because a firm subscribes to the EDLP strategy it does not necessarily forego the opportunity to discriminate.

Table 7 compares price levels of EDLP and HILO airlines for various categories. EDLP business tickets are cheaper than their HILO competitors for short-haul markets while they are actually consistently higher for leisure tickets. In short-haul markets, business tickets offered by EDLP airlines are significantly cheaper, ranging from $18.28 \%$ (for three-week advance purchase) to $25.42 \%{ }^{5}$ (for one-week advance purchase) than those offered by their HILO counterparts for all advance-purchase periods. However, leisure ticket prices in short-haul markets are not statistically different from those of their HILO counterparts. Interestingly in long-haul markets EDLP leisure tickets are statistically different and higher than HILO leisure tickets for all advance purchase periods. For example, EDLP leisure ticket prices might be between $20.33 \%$ and $51.28 \%$ higher than HILO leisure tickets, depending upon the advance purchase period. Thus

\footnotetext{
5 The relative effect of a dichotomous variable coefficient (c) on the dependent variable in semi-logarithmic equations is $100 *(\exp (c)-1)$ (Halvorsen and Palmquist 1980).
} 
there is clear evidence that there are at least some market categories where EDLP airlines do not subscribe to the "low price" component of their strategy.

In contrast, when comparing the consistency of EDLP and HILO prices, from Table 10 we can clearly see that EDLP price distributions are narrower than those of their HILO competitors. Except in a few situations, we see that EDLP prices, be it leisure or business, for all advance purchase periods, are more consistent than comparable HILO prices. The obvious suggestion from this result is the fact that EDLP airlines do take the “everyday” component of their strategy quite seriously and do not seem to offer deals or raise their prices in the same way that HILO firms do. However, the fact that there is non-zero variation should also tell us that EDLP does not mean static pricing.

\subsection{Variance in EDLP strategy}

As previously discussed, Table 6 reveals how the price level of EDLP airlines changes based on the conditions it faces. First, note that after controlling for all route-effects, EDLP airlines price their business tickets lower than their own leisure tickets by almost 11.5\%. Interestingly, this finding runs counter to what the literature had documented about HILO airlines whose leisure tickets, i.e. those that impose a Saturday night restriction, are usually offered at a discount. On the other hand, when we consider EDLP strategy in the presence of consumers with different willingness to pay, we observe that consistent with practice described by extant literature, ticket prices go up. For example, the prices of EDLP tickets increase from 8.84\% (for tickets purchased three weeks in advance) to up to $34.15 \%$ (for tickets purchased within the same week as the departure date) over the baseline 4-week advance purchase period ${ }^{6}$.

\footnotetext{
${ }^{6}$ Pairwise t-tests reveals that the coefficients $D D 7, D D 14$, and $D D 21$ are statistically different.
} 
Table 6 also reveals that ticket prices for short-haul tickets are almost 35\% lower than in long-haul markets (almost 35\% lower). As discussed earlier, EDLP short-haul prices for business tickets are less than HILO prices, while for leisure tickets they are higher. So while EDLP airlines do have lower prices from shorter distances, they strategically use their equipment size (which are fuel efficient and ideally suited for short-haul distances of less than 500 miles) to undercut competition in the business sector. Thus by passing on the savings to these consumers, they are able to aggressively promote their "low price" image to stave off competition.

Interestingly, from a price consistency perspective (Table 9), we see little variance in how EDLP price distributions look. Except for business tickets, which appear to be more consistent (lower coefficient of variation), the coefficients for other categories are statistically insignificant. Overall, the fact that five of six comparisons in Table 6 are statistically different, compared to only one of six in Table 9, suggests that with respect to projecting a price image, the ED dimension of pricing (i.e., price consistency) is more important to EDLP airlines than the LP dimension (price level).

\subsection{Monopoly pricing and EDLP strategy}

While our earlier analysis was restricted to airlines’ practice of the EDLP strategy when facing competition, we also wish examine the nature of this pricing strategy when endowed with monopoly power. We conduct analyses with two subsets of our data: the first consists of all routes in which EDLP carriers were present, while the second contains all routes in which HILO carriers competed. EDLP carriers were in a monopoly position in 59 of the 114 markets in the first dataset, while HILO carriers had a monopoly position 
in 42 of 405 markets in the second dataset $^{7}$. We apply the same models that are presented in section 3.2 with the following exceptions: 1. the EDLP main effect as well as all interaction effects are omitted from the model, since the new subsets of data consist of only one group of airlines (either EDLP or HILO) each; 2. A new dummy variable that identifies monopoly markets (EDLPmono and HILOmono for the two data sets, respectively) is added, and subsequently, RTshare and RTherf are dropped due to their obvious collinearity with this new variable; 3. The airline effects are treated as fixed rather than random, because the Hausman test rejects the null hypothesis that the coefficient estimates derived from the airline random and fixed effects models being not statistically different for the corresponding sets of data; and 4. EQUIPsize is dropped from our analysis of the EDLP data subset due to multicollinearity issues.

The results of our analysis on the EDLP data are presented in Tables 11 and 12, in which the dependent variables are ticket price and coefficient of variation respectively. Note that the coefficient estimates for EDLPmono are insignificant in both tables. This suggests that the EDLP airlines do not engage in any particular monopolistic pricing strategy and continue to operate in a similar fashion as in other markets. While empirically an interesting observation, there could potentially be a number of plausible explanations, including the possibility of limit pricing or barrier-to-entry type strategy. Alternatively EDLP firms may fear wrong signals being sent to the market if deals and promotions were created even if only for these markets. Further research is required to investigate this peculiar behavior, and is beyond the scope of the current research.

\footnotetext{
${ }^{7}$ EDLP and HILO carriers overlap in 47 markets; hence the sum of the number of markets in which the two respective types of carriers operate exceed 500 .
} 
The above results take significant meaning, particularly in light of results in Tables 13 and 14 that present the results of our analysis on the HILO data. We can clearly observe that the coefficient estimate for HILOmono in Table 13 is positive and significant while in Table 14 it is negative and significant. This suggests clear monopolistic pricing by HILO firms as might be expected from economic theories of monopoly pricing. HILO airlines not only charge higher prices in markets where they are the monopoly (higher by 15.38\%), but they also seem to restrict the range of prices they offer, i.e. little or no deals and promotions as compared to their behavior in competitive markets.

\section{DISCUSSION}

Pricing is a complex decision that involves the consideration of costs, product and market characteristics, as well as competition. The price image of a firm, is a critical component of its overall strategy which influences the types of customers that it attracts and, ultimately, its profitability (Alba et al. 1994; Desai and Talukdar 2003). While a significant body of academic research on pricing has focused at the product level, in reality pricing is a firm-level strategy - firms not only need to determine prices for a portfolio of products, but they also need to make choices regarding when, how much and how often to vary prices. There has been relatively little research to understand how product level prices may relate to the overall pricing strategy and the price image of the firm, and our research aims to fill this gap.

EDLP is a well-known pricing strategy that can enhance the price-credibility of vendors and lead to higher consumer confidence and loyalty (Ortmeyer et al. 1991). Two carriers in the airline industry are practitioners of the EDLP strategy, thus providing a 
useful context to study how this strategy is implemented. Air travel, after all, is not a onetime affair for most consumers but is replete with repeat-purchase experiences. Thus, in addition to the short-term impact of any price-setting, firms have to be concerned about the long-term perceptions and expectations of consumers with regards to their prices. From a price-image point of view, the strategy of a firm practicing EDLP is to create the expectation of low price for a consumer without needing to search extensively. Note that there are two key aspects to an EDLP strategy; the "everyday" component that refers to the consistency approach in pricing (to create a uniform and permanent belief amongst consumers), and the "low price" component that aims to provide the perception that the firm's prices are in the lower end of the market spectrum. For obvious reasons, no firm can always offer the lowest price in a market; hence it can only be expected that an EDLP firm can be "found out" online given the relative ease of search on the Internet. So the question of how EDLP is adapted to different market conditions becomes a particularly interesting one.

Industry reports suggest that firms rarely practice a strict EDLP or HILO price format; instead, they often incorporate different elements of both strategies into their actual pricing (Radice 1998). Interestingly, academic views on the adoption of a “hybrid” price format are mixed. On one hand, Ho et al. (1998) and Shankar and Bolton (2004) argue that practicing EDLP in a subset of products allows the firm to capitalize on differences in consumer demand within and across categories; on the other, Hoch et al. (1994) suggest that the benefits of a low price image accrue only if EDLP is implemented on a chain-wide basis. 
We find strong evidence that a firm does not implement EDLP in the same fashion for the entire market; rather it employs segment-specific strategies depending upon various market conditions and segment categories. While there is some anecdotal evidence of this type of strategic behavior in the grocery industry, little is known about such a practice in the online context. Our results suggest that EDLP airlines focus their low price strategy on particular market segments (business-travels and short-haul markets), while being overall consistent in their prices relative to the HILO competitors. On the other hand, for leisure tickets, we observe that prices offered by EDLP airlines are more expensive than those offered by HILO airlines in long-haul markets. Based on the success of Southwest and JetBlue, our findings may indicate that successful implementation of the EDLP strategy does not necessarily imply that airlines need to forgo their ability to price discriminate when such opportunity is available. Further, our empirical results suggest that firms appear to believe that EDLP is perpetuated more by the "ED” part rather than the "LP" part, even though it is in fact the low price dimension that is under serious threat in a low search cost environment such as in electronic markets.

Further, our results offer interesting insights to the installed base argument proposed by Hoch et al. (1994), in which they suggest that “The greater the installed base, the more difficult it will be to make EDLP pay out... because EDLP requires forgoing significant profit dollars from the installed base in search of new opportunity.” (p.23) Our analysis of EDLP airlines’ pricing in competitive versus monopoly markets (where the airlines have a large installed base of customers) reveal that these airlines do not exercise the monopoly power that they enjoy in those markets. This is an important finding in that it stands in contrast to the generic strategic preferences of a firm with 
regards to pricing. Even though economic intuition suggests that firms prefer to discriminate, e.g., charge higher prices in a tighter market and lower prices when they face competition, an EDLP firm is still constrained to maintaining this image - and it appears that EDLP airlines are creating barriers to entry by HILO competitors in markets where they enjoy monopoly power through employing the same price-image strategy as in competitive markets.

Another important observation to take note of is the fact that no EDLP airline offers its tickets through any of the online travel agents (OTA) such as Orbitz, Travelocity or Expedia. This is analogous to Wal-Mart's choice of location in the physical world: Wal-Mart, the well-known EDLP retail giant, deliberately locates its stores away from malls and other competitors who engage in frequent price discounts. By making it costly for consumers to compare prices across different stores, Wal-Mart is able to avoid head-to-head competition and defend their "always low prices” claim even when its prices may not be the lowest for any particular product. While in the physical world EDLP firms can establish such physical barriers to consumer search, the advent of electronic markets poses serious challenges to the practice of EDLP and its overall effectiveness in managing a "low price” perception. In electronic markets, airlines are essentially co-located in the same space as the transport costs associated with physical distance are absent in the online environment. Joining an OTA, while increasing the size of the potential market, also opens up a firm to price-based competition. Interestingly, Southwest and JetBlue were the only two airlines that require consumers to visit their websites directly to obtain flight schedules and pricing information. In fact, both airlines adopted various technological attempts in preventing search engines from finding out 
about their prices ${ }^{8}$. Effectively EDLP airlines appear to create barriers to searching through segment-specific implementation of EDLP and avoidance of direct comparison. Further, the manner in which EDLP are implemented show that a combination of the "everyday" and "low price" component makes up for an effective differentiation strategy.

The final element of our research that is of both academic and managerial importance is the link connecting the operational aspects of airlines and their pricing strategy. As Hoch et al. (1994) point out, "Price is not a defensible point of differentiation for a firm unless it already has the appropriate operating cost structure in place.” (p.26). Indeed, it is suggested some airlines like American do not pursue EDLP as operational infrastructure is not suited to its practice (O'Brien 1993). Operational costs vary widely among airlines and from market to market (depending on whether the airline has a hub on a given route, etc.), directly impacting the pricing structure of airlines and their ability to pursue a universal low-price strategy. Our findings show that the adoption of an EDLP format is closely associated with low variance in various operational infrastructures and relatively low cost per available seat mile. Note that however plausible these rationales may be, it is still difficult to make a causal argument with regards to cost-to-pricing versus pricing-to-cost, i.e. whether firms with low operational costs tend to choose EDLP, or an EDLP format leads to low operational costs - on one hand, one could argue that greater the cost advantage an airline achieves through operational efficiencies, the better it is able to adhere to an EDLP strategy. On the other hand, the greater the degree to which an airline practice EDLP, the better it may be able to stabilize/assess demand, making it less necessary to maintain a fleet of various different plane types and sizes, thus reducing costs. In the airline industry where a large

\footnotetext{
${ }^{8}$ JetBlue has recently started to make their offers available on major OTAs.
} 
capital investment is necessary, we could perhaps state that firms choose operational infrastructure (cost) first and pricing second.

\subsection{Limitations and future research}

Our study is one of the first to examine the practice of price-image through EDLP in an online context. Though this study provides useful insights on the strategic implementation of EDLP in electronic markets, it is subject to a number of limitations while at the same time opening up interesting opportunities for future research. First, our analysis did not include information on promotions or deals because it was not available for a majority of routes, airlines, and ticket requests. As a result, we were not able to incorporate a number of marketing mix variables in explaining differences in airlines' pricing strategies. While omission of these variables may potentially inflate the role of competitive and cost factors in our results, it should be noted that we have extensively collected all prices offered by the airlines for each particular ticket request; any such promotion or discount would have been reflected in the actual prices being offered by each individual airline. Hence the issues regarding inflation are likely to be limited. Second, we do not have demand information and in essence, we do not know which (and how many) consumers were exposed to which offer. It would be desirable to track the entire search process, i.e. where consumers begin and end their search, so that we may explicitly model the consumer decision process and obtain insights on the relative profitability of EDLP vs. HILO in electronic markets. Third, the models that we developed in this paper are descriptive in nature and are based primarily on prior theoretical assumptions and classifications of price format dimensions. Therefore, our inferences on the strategic pricing behaviors of airlines are limited to the observed 
differences between our estimations and those suggested by traditional understandings of EDLP practices. Yet, we hope that by integrating the various elements from existing literature on price format, our models can provide a comprehensive framework for further empirical explorations.

From the travel industry point of view, it would be prudent to examine the many bundling strategies practiced by OTAs and how they may affect the feasibility of EDLP. Further, it is also important to investigate if there are any differences in online EDLP practices across different vendors, brand-types, and industries. While our study offers some initial understanding of the practice of EDLP in online airline markets, generalizing this research to other industries is much needed. Particular attention is called for in the retailing of books, music, and electronic products etc. that constitutes significant portions of the \$102.1 billion online retail spending in the U.S. in 2006 alone.

Finally, the broader questions of how the nature of the low search cost distribution channel may affect the complex relationships among price format adoption, price-image of a firm, competition, consumer price sensitivity and purchase intention, and consequently the "optimal mix" (in terms of profitability) of various EDLP and HILO elements will be fruitful avenues for future research.

\section{References}

Alba, J. W., S. M. Broniarczyk, T. A. Shimp and J. E. Urbany. 1994. The Influence of Prior Beliefs, Frequency Cues, and Magnitude Cues on Consumers' Perceptions of Comparative Price Data. Journal of Consumer Research 21(2) 219-235.

Bell, D. R. and J. M. Lattin. 1998. Shopping Behavior and Consumer Preference for Store Price Format: Why "Large Basket" Shoppers Prefer EDLP. Marketing Science 17(1) 66-88. 
Berry, S. 1990. Airport Presence as Product Differentiation. The American Economic Review 80(2) 394-399.

Berry, S., M. Carnall and P. T. Spiller. 1997. Airline Hubs: Costs, Markups and the Implications of Customer Heterogeneity. NBER Working Paper \#5561.

Borenstein, S. 1989. Hubs and High Fares: Dominance and Market Power in the U.S. Airline Industry. The RAND Journal of Economics 20(3) 344-365.

Borenstein, S. and N. L. Rose. 1994. Competition and Price Dispersion in the U.S. Airline Industry. The Journal of Political Economy 102(4) 653-683.

Brueckner, J. K., N. J. Dyer and P. T. Spiller. 1992. Fare Determination in Airline Huband-Spoke Networks. The RAND Journal of Economics 23(3) 309-333.

Bryk, A. S. and Y. M. Thum. 1989. The Effects of High School Organization on Dropping Out: An Exploratory Investigation. American Educational Research Journal 26 353-383.

Chellappa, R. K., R. G. Sin and S. Siddarth. forthcoming. Price-formats as a Source of Price Dispersion: A Study of Online and Offline Prices in the Domestic U.S. Airline Markets. Information Systems Research.

Clarkson, D., Z. D. Wigder and V. Sehgal. 2005. US Travel Forecast, 2005 to 2010. Jupiter Research.

Clemons, E. K., I. Hann and L. M. Hitt. 2002. Price Dispersion and Differentiation in Online Travel: An Empirical Investigation. Management Science 48(4) 534-549.

Dana, J. D. 1998. Advance-Purchase Discounts and Price Discrimination in Competitive Markets. The Journal of Political Economy 106(2) 395-422.

Desai, K. K. and D. Talukdar. 2003. Relationship between Product Groups' Price Perceptions, Shopper's Basket Size, and Grocery Store's Overall Store Price Image. Psychology and Marketing 20(10) 903-933.

Desiraju, R., H. Nair and P. Chintagunta. 2004. Diffusion of New Pharmaceutical Drugs in Developing and Developed Nations. International Journal of Research in Marketing 21 341-357.

Gale, I. L. and T. J. Holmes. 1993. Advance-Purchase Discounts and Monopoly Allocation of Capacity. The American Economic Review 83(1) 135-146.

Griffin, M. A. and D. A. Hofman. 1997. Hierarchical Linear Models in Organizational Research: Cross-Level Interactions. Reseach Methods Forum 2 1-3.

Hausman, J. A. and W. E. Taylor. 1981. Panel Data and Unobservable Individual Effects. Econometrica 49(6) 1377-1398.

Hayes, K. J. and L. B. Ross. 1998. Is Airline Price Dispersion the Result of Careful Planning or Competitive Forces? Review of Industrial Organization 13(5) 523541.

Ho, T.-H., C. S. Tang and D. R. Bell. 1998. Rational Shopping Behavior and the Option Value of Variable Pricing. Management Science 44(December) 145-160.

Hoch, S. J., X. Dreze and M. E. Purk. 1994. EDLP, Hi-Lo, and Margin Arithmetic. Journal of Marketing 58(October) 16-27.

Lal, R. and R. C. Rao. 1997. Supermarket Competition: The Case of Every Day Low Pricing. Marketing Science 16(1) 60-80.

Lattin, J. M. and G. Ortmeyer. 1991. A Theoretical Rationale For Everyday Low Pricing By Grocery Retailers. Working Paper. 
Mendro, R. L., W. J. Webster, K. L. Bembry and T. H. Orsak. 1995. An Application of Hierarchical Linear Modeling in Determining School Effectiveness. Mimeo, Annual Meeting of the American Educational Research Association, San Francisco, CA.

Morrison, S. A. and C. Winston. 1990. The Dynamics of Airline Pricing and Competition. The American Economic Review 80(2) 389-393.

Neels, K. 2000. Congestion Pricing and the Economic Regulation of Airports. Airports in the 21st Century: Proceedings of a Conference. J. M. Rakas, G. W. Blomme and G. Gosling Transportation Research Board, The National Academies. Washington, D.C. 60-66.

Nevo, A. 2001. Measuring Market Power in the Ready-to-eat Cereal Industry. Econometrica 69(2) 307-342.

Ortmeyer, G., J. Quelch and W. Salmon. 1991. Restoring Credibility to Retail Pricing. Sloan Management Review Fall 55-66.

Radice, C. 1998. Turning Up the Heat. Progressive Grocer 65th Annual Report of the Grocery Industry(Apr) 29.

Raudenbush, S. W. and A. S. Bryk. 1989. Quantitative Models for Estimating Teacher and School Effectiveness. Multilevel Analysis of Educational Data. R. D. Bock. Academic Press, San Diego, CA: 205-232.

Shankar, V. and R. N. Bolton. 2004. An Empirical Analysis of Determinants of Retailer Pricing Strategy. Marketing Science 23(1) 28-49.

Stavins, J. 2001. Price Discrimination in the Airline Market: The Effect of Market Concentration. Review of Economics and Statistics 83(1) 200-202.

Venkatesan, R., K. Mehta and R. Bapna. 2006. Understanding the confluence of retailer characteristics, market characteristics and online pricing strategies. Decision Support Systems 42(3) 1759-1775.

Yadav, M. S. and K. Seiders. 1998. Is the Price Right? Understanding Contingent Processing in Reference Price Formation. Journal of Retailing 74(3) 311-329. 


\section{Appendix: Tables}

\section{Table 1: Description of Variables}

\begin{tabular}{|c|c|c|c|}
\hline Factor & Variable & Related Literature & Explanation \\
\hline $\begin{array}{l}\text { Ticket } \\
\text { Categories \& } \\
\text { Consumer } \\
\text { Segments }\end{array}$ & $\begin{array}{l}\text { Saturday night } \\
\text { stay-over } \\
\text { requirement } \\
\text { (BUS) } \\
\text { Advance } \\
\text { purchase period } \\
\text { (DD7, DD14, } \\
\text { DD21) }\end{array}$ & $\begin{array}{l}\text { (Gale and Holmes 1993; } \\
\text { Dana 1998; Stavins } \\
\text { 2001; Clemons et al. } \\
\text { 2002) }\end{array}$ & $\begin{array}{l}\text { BUS }=1 \text { if the observed ticket does not include a Saturday night stay-over requirement; } 0 \\
\text { otherwise. } \\
\text { DD7 = } 1 \text { if the observed ticket is generated within } 0-7 \text { days of departure date; } 0 \text { otherwise. } \\
\text { DD14 = } 1 \text { if the observed ticket is generated within } 7-14 \text { days of departure date; } 0 \text { otherwise. } \\
\text { DD21 = } 1 \text { if the observed ticket is generated within } 14-21 \text { days of departure date; } 0 \\
\text { otherwise. }\end{array}$ \\
\hline \multirow{2}{*}{$\begin{array}{l}\text { Market } \\
\text { Characteristics }\end{array}$} & $\begin{array}{l}\text { Distance } \\
\text { (shorthaul) }\end{array}$ & $\begin{array}{l}\text { (Borenstein 1989; Berry } \\
\text { et al. 1997; Hayes and } \\
\text { Ross 1998; Stavins 2001) }\end{array}$ & $\begin{array}{l}\text { shorthaul = } 1 \text { if the non-stop distance between the origin and the destination airports on the } \\
\text { observed route is equal to or less than } 500 \text { miles; } 0 \text { otherwise. }\end{array}$ \\
\hline & $\begin{array}{l}\text { Herfindahl Index } \\
\text { (RTherf) }\end{array}$ & $\begin{array}{l}\text { (Borenstein 1989; } \\
\text { Borenstein and Rose } \\
\text { 1994) }\end{array}$ & RTherf is the Herfindahl index for all passengers on the observed route. \\
\hline \multirow{2}{*}{$\begin{array}{l}\text { Market } \\
\text { Power }\end{array}$} & $\begin{array}{l}\text { Hub } \\
\text { (hub) }\end{array}$ & $\begin{array}{l}\text { Borenstein 1989; } \\
\text { Borenstein 1991; Berry } \\
\text { et al. 1997; Hayes and } \\
\text { Ross 1998) }\end{array}$ & $\begin{array}{l}\text { hub }=1 \text { if the origin and/or destination airport(s) in a given route is (are) a hub(s) for the } \\
\text { observed airline; } 0 \text { otherwise. }\end{array}$ \\
\hline & $\begin{array}{l}\text { Market Share } \\
\text { (RTshare) }\end{array}$ & $\begin{array}{l}\text { (Borenstein 1989; } \\
\text { Borenstein and Rose } \\
\text { 1994) }\end{array}$ & RTshare is the observed carrier's share of passengers on the observed route. \\
\hline \multirow{3}{*}{$\begin{array}{l}\text { Operational/ } \\
\text { Cost Structure }\end{array}$} & $\begin{array}{l}\text { Frequency } \\
\text { (freq) }\end{array}$ & $\begin{array}{l}\text { (Borenstein and Rose } \\
\text { 1994; Hayes and Ross } \\
\text { 1998) }\end{array}$ & $\begin{array}{l}\text { freq is the observed carrier's weekly average number of flights scheduled for departure from } \\
\text { the origin to the destination on a given route. }\end{array}$ \\
\hline & $\begin{array}{l}\text { Cost per available } \\
\text { seat-mile } \\
\text { (CASM) }\end{array}$ & (Borenstein 1989) & CASM is the cost per available seat-mile (in cents) of the observed airline. \\
\hline & $\begin{array}{l}\text { Aircraft Size } \\
\text { (EQUIPsize) }\end{array}$ & (Borentein 1989) & $\begin{array}{l}\text { EQUIPsize is the average size of the aircrafts operated by the observed airline on a given } \\
\text { route. }\end{array}$ \\
\hline Price-format & EDLP & New variable & EDLP = 1 if the ticket is offered by an EDLP airline (Southwest or JetBlue); 0 otherwise. \\
\hline
\end{tabular}


Table 2: Descriptive Statistics on the Full Sample $(\mathrm{N}=272,362)$

\begin{tabular}{|l|r|r|r|r|r|r|r|r|r|r|r|r|r|r|r|r|r|}
\hline & MEAN & STD & Min & Max & \multicolumn{10}{|c|}{ Correlation Matrix } & \\
\hline Price & 328.16 & 265.88 & 89.00 & 2959.00 & 1.00 & & & & & & & & & & & \\
\hline EDLP & 0.12 & 0.33 & 0.00 & 1.00 & -0.42 & 1.00 & & & & & & & & & & & \\
\hline BUS & 0.50 & 0.50 & 0.00 & 1.00 & 0.02 & 0.02 & 1.00 & & & & & & & & & \\
\hline DD7 & 0.25 & 0.43 & 0.00 & 1.00 & 0.18 & 0.01 & -0.01 & 1.00 & & & & & & & & & \\
\hline DD14 & 0.25 & 0.43 & 0.00 & 1.00 & 0.00 & -0.01 & 0.00 & -0.33 & 1.00 & & & & & & & & \\
\hline DD21 & 0.25 & 0.44 & 0.00 & 1.00 & -0.09 & 0.00 & 0.00 & -0.33 & -0.34 & 1.00 & & & & & & & \\
\hline freq & 42.40 & 39.61 & 0.00 & 192.08 & -0.21 & 0.36 & -0.01 & 0.00 & -0.01 & 0.00 & 1.00 & & & & & & \\
\hline hub & 0.74 & 0.44 & 0.00 & 1.00 & 0.03 & -0.08 & -0.01 & 0.00 & 0.00 & 0.00 & 0.37 & 1.00 & & & & & \\
\hline RTshare & 0.54 & 0.31 & 0.00 & 1.00 & -0.23 & 0.49 & 0.01 & 0.00 & -0.02 & 0.01 & 0.57 & 0.28 & 1.00 & & & & \\
\hline RTherf & 0.57 & 0.22 & 0.00 & 1.00 & -0.31 & 0.48 & 0.02 & 0.01 & -0.02 & 0.01 & 0.19 & 0.01 & 0.68 & 1.00 & & & \\
\hline shorthaul & 0.37 & 0.48 & 0.00 & 1.00 & -0.44 & 0.29 & 0.02 & 0.01 & -0.01 & 0.01 & 0.04 & -0.07 & 0.20 & 0.37 & 1.00 & & \\
\hline CASM & 11.59 & 2.56 & 6.13 & 16.13 & 0.25 & -0.55 & -0.02 & 0.00 & 0.01 & 0.00 & -0.33 & -0.04 & -0.39 & -0.28 & -0.06 & 1.00 & \\
\hline EQUIPsize & 139.21 & 21.40 & 72.00 & 249.00 & 0.02 & -0.06 & -0.01 & 0.00 & 0.01 & 0.00 & 0.03 & -0.09 & 0.03 & 0.01 & -0.21 & -0.09 & 1.00 \\
\hline
\end{tabular}

Table 3: Summary Statistics on Selected Operational Details - EDLP vs. HILO Carriers

\begin{tabular}{|c|c|c|c|c|c|}
\hline & & Min & Mean & Max & Variance \\
\hline \multirow{2}{*}{$\begin{array}{c}\text { Number of Different } \\
\text { Types of Aircraft } \\
\text { Operated }^{9}\end{array}$} & $\begin{array}{l}\text { EDLP } \\
\text { Carriers }\end{array}$ & 1 & 1 & 1 & 0 \\
\hline & $\begin{array}{l}\text { HILO } \\
\text { Carriers }\end{array}$ & 2 & 4.33 & 8 & 4.79 \\
\hline \multirow{2}{*}{$\begin{array}{l}\text { Cost Per Available } \\
\text { Seat Mile (in cents) }\end{array}$} & $\begin{array}{l}\text { EDLP } \\
\text { Carriers }\end{array}$ & 6.13 & 6.87 & 7.6 & 1.08 \\
\hline & $\begin{array}{l}\text { HILO } \\
\text { Carriers }\end{array}$ & 7.26 & 10.89 & 16.13 & 7.27 \\
\hline
\end{tabular}

\footnotetext{
${ }^{9}$ Different sub-models or configurations under the same model (e.g. Boeing 737-400 and Boeing 737-500) are considered as the same type of aircraft.
} 
Table 4: Comparison of Goodness of Fit

\begin{tabular}{|l|c|c|c|}
\hline \multirow{2}{*}{ Effect/Index } & \multicolumn{3}{|c|}{$\begin{array}{c}\text { Estimate } \\
\text { (standard error) }\end{array}$} \\
\cline { 2 - 4 } & 2SLS & NULL HLM & FULL HLM \\
\hline$\hat{\varphi}$ (Airline Random Effect) & -- & $\begin{array}{c}0.01145^{\star \star} \\
(0.0053)\end{array}$ & $\begin{array}{c}0.0032^{\star \star} \\
(0.0019)\end{array}$ \\
\hline$\hat{\tau}$ (Route Random Effect) & -- & $\begin{array}{c}0.1705^{\star \star \star} \\
(0.0158)\end{array}$ & $\begin{array}{c}0.1353^{\star \star \star} \\
(0.0125)\end{array}$ \\
\hline$\hat{\psi}$ (Random Interaction Effect) & -- & $\begin{array}{c}0.02045^{\star \star \star} \\
(0.0015)\end{array}$ & $\begin{array}{c}0.0154^{\star \star \star} \\
(0.0012)\end{array}$ \\
\hline$\widehat{\sigma^{2}}$ (Residual) & $0.1115^{\star \star \star}$ & $\begin{array}{c}0.1235^{\star \star \star} \\
(0.0004)\end{array}$ & $\begin{array}{c}0.1051^{\star \star \star} \\
(0.0003)\end{array}$ \\
\hline-2 LL & $(0.0003)$ & 159762 & 125876 \\
\hline BIC & 136716 & 159762 & 125876 \\
\hline Sum of Residual-Squared & 136728 & 25798.27 & 21944.30 \\
\hline
\end{tabular}

${ }^{*} \mathbf{p}<0.10 ;{ }^{* *} \mathbf{p}<0.05 ;{ }^{* * *} \mathbf{p}<.01$ (Same notation for all tables) 
Table 5: Results of Model 1 - Price Level

\begin{tabular}{|c|c|}
\hline Variable & $\begin{array}{c}\text { Estimate } \\
\text { (standard error) }\end{array}$ \\
\hline Intercept & $\begin{array}{l}5.7589 \star \star \star \\
(0.3875)\end{array}$ \\
\hline EDLP & $\begin{array}{l}0.1931^{\star \star \star} \\
(0.0694)\end{array}$ \\
\hline BUS & $\begin{array}{l}0.1255^{\star \star \star} \\
(0.0015)\end{array}$ \\
\hline DD7 & $\begin{array}{l}0.3018^{\star \star \star} \\
(0.0021)\end{array}$ \\
\hline DD14 & $\begin{array}{l}0.0772^{\star \star \star} \\
(0.0021)\end{array}$ \\
\hline DD21 & $\begin{array}{c}0.0014 \\
(0.0020)\end{array}$ \\
\hline $\ln ($ freq) & $\begin{array}{l}-0.0240 * \star \star \\
(0.0036)\end{array}$ \\
\hline hub & $\begin{array}{l}-0.0649 * \star \star \\
(0.0230)\end{array}$ \\
\hline RTshare & $\begin{array}{l}0.1667^{\star \star \star} \\
(0.0822)\end{array}$ \\
\hline$\widehat{\text { RTherf }}$ & $\begin{array}{c}-1.5675^{\star \star \star} \\
(0.3659)\end{array}$ \\
\hline shorthaul & $\begin{array}{l}-0.1993^{\star \star \star} \\
(0.0775)\end{array}$ \\
\hline $\ln (\mathrm{CASM})$ & $\begin{array}{l}0.3611^{* \star *} \\
(0.0803)\end{array}$ \\
\hline In(EQUIPsize) & $\begin{array}{l}-0.0408 \\
(0.0621)\end{array}$ \\
\hline$E D L P \times B U S$ & $\begin{array}{l}-0.2474^{\star \star \star} \\
(0.0075)\end{array}$ \\
\hline$E D L P \times D D 7$ & $\begin{array}{l}-0.0080 \\
(0.0106)\end{array}$ \\
\hline$E D L P \times D D 14$ & $\begin{array}{l}0.0480^{\star \star \star} \\
(0.0107)\end{array}$ \\
\hline$E D L P \times D D 21$ & $\begin{array}{l}0.0834^{\star \star \star} \\
(0.0106)\end{array}$ \\
\hline$E D L P \times$ shorthaul & $\begin{array}{c}-0.2310^{\star \star \star \star} \\
(0.0825)\end{array}$ \\
\hline$E D L P \times h u b$ & $\begin{array}{c}0.1375 \\
(0.0975)\end{array}$ \\
\hline $\mathrm{N}$ & 209558 \\
\hline$-2 \mathrm{LL}$ & 125875.8 \\
\hline
\end{tabular}

Table 6: Interpretation of Effects -

The "Low Price” Dimension of EDLP

\begin{tabular}{|c|c|c|}
\hline Effect & Baseline & $\begin{array}{l}\text { Estimate } \\
\text { (S.E.) }\end{array}$ \\
\hline BUS & $\begin{array}{l}\text { Leisure tickets (with } \\
\text { weekend restriction) }\end{array}$ & $\begin{array}{c}-0.1219^{* \star \star} \\
(0.0074)\end{array}$ \\
\hline DD7 & $\begin{array}{l}\text { Four-week advance } \\
\text { purchase tickets }\end{array}$ & $\begin{array}{l}0.2938^{\star \star \star} \\
(0.0104)\end{array}$ \\
\hline DD14 & $\begin{array}{l}\text { Four-week advance } \\
\text { purchase tickets }\end{array}$ & $\begin{array}{l}0.1252^{\star \star \star} \\
(0.0105)\end{array}$ \\
\hline DD21 & $\begin{array}{l}\text { Four-week advance } \\
\text { purchase tickets }\end{array}$ & $\begin{array}{c}0.0847^{\star \star \star} \\
(0.0104)\end{array}$ \\
\hline shorthaul & Long-haul markets & $\begin{array}{c}-0.4302^{\star * \star} \\
(0.1073)\end{array}$ \\
\hline hub & Non-hub markets & $\begin{array}{c}0.0726 \\
(0.0949)\end{array}$ \\
\hline
\end{tabular}


Table 7: Comparison of Price Level - EDLP vs. HILO Carriers

$(D . V .=$ Price; Baseline $=$ HILO $)$

\begin{tabular}{|c|c|c|c|c|}
\hline \multirow{3}{*}{$\begin{array}{l}\text { Micket Category } \\
\text { Weekend Restriction }\end{array}$} & \multicolumn{4}{|c|}{ Short-haul } \\
\hline & \multicolumn{2}{|c|}{ Non-hub Markets } & \multicolumn{2}{|c|}{ Hub Markets } \\
\hline & Business & Leisure & Business & Leisure \\
\hline DD7 & $-0.2933^{\star \star *}$ & -0.0459 & -0.1558 & 0.0916 \\
\hline DD14 & $-0.2373^{\star \star}$ & 0.0101 & -0.0998 & 0.1476 \\
\hline DD21 & $-0.2019^{\star \star}$ & 0.0455 & -0.0644 & 0.1830 \\
\hline DD28 & $-0.2853^{\star \star \star}$ & -0.0379 & -0.1478 & 0.0996 \\
\hline \multirow{2}{*}{ Ticket Category } & \multicolumn{4}{|c|}{ Long-haul } \\
\hline & \multicolumn{2}{|c|}{ Non-hub Markets } & \multicolumn{2}{|c|}{ Hub Markets } \\
\hline Weekend Restriction & Business & Leisure & Business & Leisure \\
\hline DD7 & -0.0623 & $0.1851^{\star \star \star}$ & 0.0752 & $0.3226^{\star \star \star}$ \\
\hline DD14 & -0.0063 & $0.2411^{\star \star \star}$ & 0.1312 & $0.3786^{\star \star \star}$ \\
\hline DD21 & 0.0291 & $0.2765^{\star \star \star}$ & 0.1666 & $0.4140^{\star \star \star}$ \\
\hline DD28 & -0.0543 & $0.1931^{\star \star \star}$ & 0.0832 & $0.3306^{\star \star \star}$ \\
\hline
\end{tabular}


Table 8: Results of Model 2 Coefficient of Variation

\begin{tabular}{|c|c|}
\hline & $\begin{array}{c}\text { Estimate } \\
\text { (standard error) }\end{array}$ \\
\hline Intercept & $\begin{array}{c}0.0568 \\
(0.0411) \\
\end{array}$ \\
\hline EDLP & $\begin{array}{c}-0.0847^{\star \star \star} \\
(0.0229) \\
\end{array}$ \\
\hline BUS & $\begin{array}{l}-0.0646^{\star \star \star} \\
(0.0036)\end{array}$ \\
\hline DD7 & $\begin{array}{l}0.0654^{\star \star *} \\
(0.0051)\end{array}$ \\
\hline DD14 & $\begin{array}{l}0.0537^{\star \star \star} \\
(0.0051)\end{array}$ \\
\hline DD21 & $\begin{array}{c}0.0070 \\
(0.0051)\end{array}$ \\
\hline hub & $\begin{array}{c}0.0059 \\
(0.0075)\end{array}$ \\
\hline$\widehat{\text { RTshare }}$ & $\begin{array}{l}0.0567^{\star *} \\
(0.0231)\end{array}$ \\
\hline$\widehat{R T h e r f}$ & $\begin{array}{c}0.0138 \\
(0.0778) \\
\end{array}$ \\
\hline shorthaul & $\begin{array}{c}0.0032 \\
(0.0162)\end{array}$ \\
\hline CASM & $\begin{array}{l}0.0059^{\star \star \star} \\
(0.0010)\end{array}$ \\
\hline EQUIPsize & $\begin{array}{c}0.0000 \\
(0.0001)\end{array}$ \\
\hline$E D L P \times B U S$ & $\begin{array}{l}0.0317^{\star} \\
(0.0171)\end{array}$ \\
\hline$E D L P \times D D 7$ & $\begin{array}{l}-0.0248 \\
(0.0243)\end{array}$ \\
\hline$E D L P \times D D 14$ & $\begin{array}{l}-0.0434^{*} \\
(0.0242)\end{array}$ \\
\hline$E D L P \times D D 21$ & $\begin{array}{c}0.0265 \\
(0.0242)\end{array}$ \\
\hline$E D L P \times$ shorthaul & $\begin{array}{l}-0.0403 \\
(0.0275)\end{array}$ \\
\hline$E D L P \times h u b$ & $\begin{array}{c}0.0264 \\
(0.0395) \\
\end{array}$ \\
\hline $\mathrm{N}$ & 5422 \\
\hline$-2 \mathrm{LL}$ & -6158.1 \\
\hline
\end{tabular}

Table 9: Interpretation of Effects -

The "Everyday" Dimension of EDLP

\begin{tabular}{|c|c|c|}
\hline Effect & Baseline & $\begin{array}{l}\text { Estimate } \\
\text { (S.E.) }\end{array}$ \\
\hline BUS & $\begin{array}{c}\text { Leisure tickets (with } \\
\text { weekend } \\
\text { restriction) }\end{array}$ & $\begin{array}{r}-0.0329^{\star \star} \\
(0.0167)\end{array}$ \\
\hline DD7 & $\begin{array}{c}\text { Four-week advance } \\
\text { purchase tickets }\end{array}$ & $\begin{array}{l}0.0406^{\star} \\
(0.0237)\end{array}$ \\
\hline DD14 & $\begin{array}{c}\text { Four-week advance } \\
\text { purchase tickets }\end{array}$ & $\begin{array}{c}0.0104 \\
(0.0236)\end{array}$ \\
\hline DD21 & $\begin{array}{c}\text { Four-week advance } \\
\text { purchase tickets }\end{array}$ & $\begin{array}{l}0.03343 \\
(0.0236)\end{array}$ \\
\hline shorthaul & Long-haul markets & $\begin{array}{l}-0.0371 \\
(0.0302)\end{array}$ \\
\hline hub & Non-hub markets & $\begin{array}{c}0.0324 \\
(0.0387)\end{array}$ \\
\hline
\end{tabular}


Table 10: Comparison of Price Variability - EDLP vs. HILO Carriers

(D.V. = Coefficient of Variation; Baseline $=$ HILO)

\begin{tabular}{|c|c|c|c|c|}
\hline \multirow{3}{*}{$\begin{array}{l}\text { Ticket Category } \\
\text { Weekend Restriction }\end{array}$} & \multicolumn{4}{|c|}{ Short-haul } \\
\hline & \multicolumn{2}{|c|}{ Non-hub Markets } & \multicolumn{2}{|c|}{ Hub Markets } \\
\hline & Business & Leisure & Business & Leisure \\
\hline DD7 & $-0.1181^{\star \star \star}$ & $-0.1498^{\star \star \star}$ & $-0.0917^{\star \star}$ & $-0.1234^{* \star *}$ \\
\hline DD14 & $-0.1367^{* \star *}$ & $-0.1684^{\star \star \star}$ & $-0.1102^{\star \star \star \star}$ & $-0.1419^{\star \star \star *}$ \\
\hline DD21 & $-0.0669 \star \star$ & $-0.0985^{\star \star \star}$ & -0.0404 & $-0.0721^{*}$ \\
\hline DD28 & $-0.0933^{\star \star \star}$ & $-0.1250^{\star \star \star}$ & $-0.0669^{*}$ & $-0.0986^{\star *}$ \\
\hline \multirow{2}{*}{ Ticket Category } & \multicolumn{4}{|c|}{ Long-haul } \\
\hline & \multicolumn{2}{|c|}{ Non-hub Markets } & \multicolumn{2}{|c|}{ Hub Markets } \\
\hline Weekend Restriction & Business & Leisure & Business & Leisure \\
\hline DD7 & $-0.0778^{\star \star \star}$ & $-0.1095^{\star \star \star}$ & -0.0514 & $-0.0831^{*}$ \\
\hline DD14 & $-0.0963^{\star \star \star}$ & $-0.1280^{\star \star \star}$ & -0.0699 & $-0.1016^{\star \star}$ \\
\hline DD21 & -0.0265 & $-0.0582^{\star \star}$ & -0.0001 & -0.0318 \\
\hline DD28 & $-0.0530^{* *}$ & $-0.0847^{\star \star \star}$ & -0.0265 & -0.0582 \\
\hline
\end{tabular}

(Negative values represent higher price consistency) 
Table 11: EDLP Prices in Competitive vs.

Monopoly Markets - Price Level

\begin{tabular}{|l|c|}
\hline \multicolumn{1}{|c|}{ Variable } & $\begin{array}{c}\text { Estimate } \\
\text { (standard error) }\end{array}$ \\
\hline \multirow{2}{*}{ Intercept } & $\begin{array}{c}5.1495^{\star \star \star} \\
(0.4803)\end{array}$ \\
\hline \multirow{2}{*}{ weekday } & $\begin{array}{c}-0.1153^{\star \star \star} \\
(0.0019)\end{array}$ \\
\hline \multirow{2}{*}{ DD7 } & $\begin{array}{c}0.2666^{\star \star \star} \\
(0.0027)\end{array}$ \\
\hline \multirow{2}{*}{ DD14 } & $\begin{array}{l}0.0248^{\star \star \star} \\
(0.0028)\end{array}$ \\
\hline DD21 & $0.0386^{\star \star \star}$ \\
& $(0.0027)$ \\
\hline In(freq) & -0.0114 \\
& $(0.0152)$ \\
\hline hub & 0.0783 \\
& $(0.0487)$ \\
\hline \multirow{2}{*}{ Shorthaul } & $-0.6903^{\star \star \star}$ \\
& $(0.0469)$ \\
\hline In(CASM) & 0.1524 \\
\hline EDLPmono & $(0.2497)$ \\
\hline & 0.0505 \\
& $(0.0466)$ \\
\hline N & \\
\hline -2LL & 33937 \\
\hline & -20573.3 \\
\hline
\end{tabular}

Table 12: EDLP Prices in Competitive vs.

Monopoly Markets - Price Variability

\begin{tabular}{|c|c|}
\hline Variable & $\begin{array}{c}\text { Estimate } \\
\text { (standard error) }\end{array}$ \\
\hline Intercept & $\begin{array}{l}0.2779 \star \star \star \\
(0.0466)\end{array}$ \\
\hline weekday & $\begin{array}{c}-0.0358^{\star \star \star} \\
(0.0039)\end{array}$ \\
\hline DD7 & $\begin{array}{l}0.0360 \star \star \star \\
(0.0056)\end{array}$ \\
\hline DD14 & $\begin{array}{l}0.0175^{\star \star \star} \\
(0.0055)\end{array}$ \\
\hline DD21 & $\begin{array}{l}0.0273^{\star \star \star} \\
(0.0056)\end{array}$ \\
\hline freq & $\begin{array}{l}0.0007^{\star \star \star} \\
(0.0001)\end{array}$ \\
\hline hub & $\begin{array}{l}-0.0119 \\
(0.0089)\end{array}$ \\
\hline shorthaul & $\begin{array}{l}-0.0124 \\
(0.0085)\end{array}$ \\
\hline CASM & $\begin{array}{l}-0.0335^{\star \star \star} \\
(0.0066)\end{array}$ \\
\hline EDLPmono & $\begin{array}{c}0.0105 \\
(0.0086)\end{array}$ \\
\hline$N$ & 714 \\
\hline$-2 L L$ & -1995.1 \\
\hline
\end{tabular}


Table 13: HILO Prices in Competitive vs. Monopoly Markets - Price Level

\begin{tabular}{|c|c|}
\hline Variable & $\begin{array}{c}\text { Estimate } \\
\text { (standard error) }\end{array}$ \\
\hline Intercept & $\begin{array}{l}4.6750 \star \star \star \\
(0.1651)\end{array}$ \\
\hline weekday & $\begin{array}{l}0.1354^{\star \star \star} \\
(0.0014)\end{array}$ \\
\hline DD7 & $\begin{array}{l}0.3184^{\star \star \star} \\
(0.0020)\end{array}$ \\
\hline DD14 & $\begin{array}{l}0.0790^{\star \star \star} \\
(0.0020)\end{array}$ \\
\hline DD21 & $\begin{array}{c}0.0017 \\
(0.0020) \\
\end{array}$ \\
\hline In(freq) & $\begin{array}{l}-0.0169 * \star \star \\
(0.0006)\end{array}$ \\
\hline hub & $\begin{array}{l}-0.0695^{\star \star \star} \\
(0.0036)\end{array}$ \\
\hline shorthaul & $\begin{array}{l}-0.4000^{\star \star \star} \\
(0.0489)\end{array}$ \\
\hline In(CASM) & $\begin{array}{l}0.3531^{\star \star \star} \\
(0.0653)\end{array}$ \\
\hline In(EQUIPsize) & $\begin{array}{l}0.0305^{\star \star \star} \\
(0.0099)\end{array}$ \\
\hline HILOmono & $\begin{array}{l}0.1431^{\star * \star} \\
(0.0416)\end{array}$ \\
\hline $\mathrm{N}$ & 238425 \\
\hline$-2 \mathrm{LL}$ & 163972.3 \\
\hline
\end{tabular}

Table 14: HILO Prices in Competitive vs. Monopoly Markets - Price Variability

\begin{tabular}{|c|c|}
\hline Variable & $\begin{array}{c}\text { Estimate } \\
\text { (standard error) }\end{array}$ \\
\hline Intercept & $\begin{array}{l}0.0703^{\star \star \star} \\
(0.0203)\end{array}$ \\
\hline weekday & $\begin{array}{c}-0.0639 * \star \star \\
(0.0034)\end{array}$ \\
\hline DD7 & $\begin{array}{l}0.0644^{\star \star \star} \\
(0.0047)\end{array}$ \\
\hline DD14 & $\begin{array}{l}0.0555^{\star \star *} \\
(0.0047)\end{array}$ \\
\hline DD21 & $\begin{array}{l}0.0110 * * \\
(0.0047)\end{array}$ \\
\hline freq & $\begin{array}{l}0.0002^{\star *} \\
(0.0001)\end{array}$ \\
\hline hub & $\begin{array}{l}0.0138^{\star \star \star} \\
(0.0053)\end{array}$ \\
\hline shorthaul & $\begin{array}{c}0.0033 \\
(0.0101) \\
\end{array}$ \\
\hline CASM & $\begin{array}{l}0.0053^{\star \star \star} \\
(0.0009)\end{array}$ \\
\hline EQUIPsize & $\begin{array}{c}0.0001 \\
(0.0001)\end{array}$ \\
\hline HILOmono & $\begin{array}{l}-0.0153^{*} \\
(0.0090) \\
\end{array}$ \\
\hline $\mathrm{N}$ & 6207 \\
\hline$-2 \mathrm{LL}$ & -6772.4 \\
\hline
\end{tabular}

